\title{
Level of CD8 T Lymphocytes Activation in HIV-Infected Pregnant Women: In the Context of CD38 and HLA-DR Activation Markers
}

\author{
Stanslaus Musyoki, ${ }^{1}$ Simeon Mining, ${ }^{2}$ and Paul Nyongesa ${ }^{3}$ \\ ${ }^{1}$ Kisii University, P.O. Box 408-40200, Kisii, Kenya \\ ${ }^{2}$ Department of Immunology, Moi University, P.O. Box 4606-30100, Eldoret, Kenya \\ ${ }^{3}$ Department of Reproductive Health, Moi University, P.O. Box 4606-30100, Eldoret, Kenya \\ Correspondence should be addressed to Stanslaus Musyoki; maketish@yahoo.com
}

Received 3 September 2013; Revised 28 October 2013; Accepted 26 November 2013; Published 22 January 2014

Academic Editor: Geoffrey Gottlieb

Copyright (C) 2014 Stanslaus Musyoki et al. This is an open access article distributed under the Creative Commons Attribution License, which permits unrestricted use, distribution, and reproduction in any medium, provided the original work is properly cited.

\begin{abstract}
Background. To date the effect of pregnancy on the immune activation of CD8 T cells that may affect HIV disease progression has not been well studied and remains unclear. Objective. To determine the effect of pregnancy on CD8 T lymphocyte activation and its relationship with CD4 count in HIV infected pregnant women. Study Design. Case control. Study Site. AMPATH and MTRH in Eldoret, Kenya. Study Subjects. Newly diagnosed asymptomatic HIV positive pregnant and nonpregnant women with no prior receipt of antiretroviral medications. Study Methods. Blood samples were collected from the study participants and levels of activated CD8 T lymphocytes (CD38 and HLA-DR) were determined using flow cytometer and correlated with CD4 counts of the study participants. The descriptive data focusing on frequencies, correlation, and cross-tabulations was statistically determined. Significance of the results was set at $P<0.05$. Results. HIV positive pregnant women had lower activated CD8 T lymphocyte counts than nonpregnant HIV positive women. Activated CD8 T lymphocyte counts were also noted to decrease in the second and third trimesters of pregnancy. Conclusion. Pregnancy has a significant suppression on CD8+ T lymphocyte immune activation during HIV infections. Follow-up studies with more control arms could confirm the present study results.
\end{abstract}

\section{Introduction}

Cytotoxic T lymphocyte (CD8) cell activation is a major cause of HIV pathology [1]. The expression of the activation markers CD38 and HLA-DR on T cells is an indicator of cell activation [2]. HIV infection activates CD8 $\mathrm{T}$ cells resulting in their expansion and expression of HLA-DR antigens [3]. To date the effect of pregnancy on the immune activation of CD8 T cells that may affect HIV disease progression has not been well studied and remains unclear. Thus, the study set to investigate the levels of activated $\mathrm{CD} 8^{+} \mathrm{T}$ surface markers (CD38 and HLA-DR) would lead to a better understanding of the immunological relationship of HIV and pregnancy. The objective of the study was therefore to compare CD8 T lymphocyte activation surface markers (CD38 and HLADR) levels in pregnant and nonpregnant women with HIV infection. The study used CD8 cellular immune activation surface markers $\left(\mathrm{CD}^{+} / \mathrm{HLA}-\mathrm{DR} / \mathrm{CD} 38\right)$ because $\mathrm{CD} 8^{+}$cellular activation, as opposed to $\mathrm{CD}^{+}$activation, is more predictive of long-term immunologic responses as $\mathrm{CD} 4^{+}$cells are infected by HIV and are more likely to be removed through apoptosis [4].

\section{Materials and Methods}

The investigation was done in Eldoret, Kenya, at Academic Model for Providing Access to Healthcare (AMPATH) centre outpatient clinics and Moi Teaching and Referral Hospital (MTRH)-Mother Child Health Care (MCH) Clinics. AMPATH was started in 2000 as part of collaboration between Moi University (MU), MTRH, and a consortium of American universities led by Indiana University of the United States. AMPATH is the largest HIV/AIDS treatment 
and care program in Kenya. MTRH is the second largest hospital in Kenya and serves referral patients from Rift Valley and Western Kenya. AMPATH aims at a comprehensive care for HIV-infected patients, enhancing education and research in HIV/AIDS.

In a case-controlled study design asymptomatic HIVpositive pregnant and nonpregnant women with no prior receipt of antiretroviral medications and ages $\geq 18$ years and $\leq 40$ years were evaluated. A study sample guidelinequestionnaire was used to enquire from the study participants the possible period of HIV infection with $\geq 6$ months set as the maximum period of HIV infection to recruit the study participants. This was done for both study group and controls since it is naturally difficult to recruit participants of exactly similar time after infection; this was one of the study limitations. Women with a history or diagnosis of any complications in pregnancy (previous or present), for example, miscarriages, tumors, diabetic mellitus, pneumonia, influenza, herpes, autoimmunity, or evidence of acute infection, and untreated medical illness, for example, coinfections in pregnancy, were excluded from the study. Consecutive sampling technique was used to recruit thirty-six HIV-infected pregnant women as the study subjects and thirty-six HIV-infected nonpregnant women as control group. Specific levels of $\mathrm{CD} 8^{+}$cellular immune activation markers (CD8 $\left.{ }^{+} / \mathrm{HLA}-\mathrm{DR} / \mathrm{CD} 38\right)$ were determined and correlated with $\mathrm{CD} 4$ counts between the two groups.

Laboratory analysis to determine the levels of activated CD8 T lymphocytes was performed using a flow-cytometer FACSCalibur (BD Biosciences, San Jose, CA, USA). The flow-cytometer machine was equipped with $635 \mathrm{~nm}$ and $488 \mathrm{~nm}$ lasers and could detect four color fluorescence with emissions detectable in the ranges of $515-545 \mathrm{~nm}, 562-$ $607 \mathrm{~nm},>650 \mathrm{~nm}$, and $652-608 \mathrm{~nm}$. The machine also set to discriminate using $>650$ channel. Blood samples were stained within 48 hours of collection and analyzed within 24 hours of staining. CD $8^{+} / \mathrm{HLA}-\mathrm{DR} / \mathrm{CD} 38$ surface markers were then labeled and analysed using CD38 and HLA-DR monoclonal antibodies conjugated with FITC: fluorescein isothiocyanate; PE: phycoerythrin; PE-C5: phycoerythrincyanine5; APC: allophycocyanin. processing of the samples was done using FACS Lyse/No wash method, acquired from a BD FACSCalibur instrument. For each sample mixed with anticoagulant EDTA, tubes were prepared. Twenty (20) $\mu \mathrm{L}$ of the antibodies were put in each tube and vortexed. Then $50 \mu \mathrm{L}$ of the blood sample was added, vortexed, and incubated for 15 minutes. After staining and following incubation, cells were lysed with $450 \mu \mathrm{L}$ of BDFacLyse reagent and incubated for at least another 15 minutes. Live gating based on forward- and side-scatter properties was set on the $\mathrm{CD}^{+}$ and $\mathrm{CD}^{+}$lymphocyte fraction. Live gating was used to collect 10000 events by FSC and SSC cytogram with a gate set on the $\mathrm{CD}^{+}$and $\mathrm{CD}^{+}$lymphocyte fraction. The cells were gated based on forward- and side-scatter properties. The percentage of cells $\mathrm{CD}^{+}{ }^{+} \mathrm{T}$ cells expressing CD38 and HLA-DR surface markers was then read using the cell quest pro software (BD Biosciences, San Jose, CA, USA). All the data was recorded on a standard case report forms, a tool developed for this study. Statistical analysis of descriptive data focusing on frequencies, correlation, and cross-tabulations was determined using statistical package for social sciences (SPSS) version 16.0 (Norusis, SPSS, Chicago, IL, USA). Nonparametric methods were used to statistically evaluate the data and compare tests since the data was not normally distributed. Significance of the results was set at $P<0.05$.

The study was given ethical approval by Institutional Research and Ethics Committee (IREC) from Moi University/Moi Teaching and Referral Hospital (approval number is 000388). The study procedures did not interfere in any manner with the routine clinical care provided to patients enrolled in the study. Informed and voluntary consent by each subject was sought before any data was collected from the subjects. The purpose, procedures, and risks and benefits of the study were also discussed with the subject. The participants were given adequate opportunities to discuss and contemplate their participation. The participants also retained the right to refuse to answer individual questions or to discontinue study participation without jeopardy. The participants had privacy and all information was treated as confidential.

\section{Results}

Social-economic and demographic characteristics have been shown in Table 1 . The mean age of the 72 women included in this analysis at the time that it was performed was 30.35 years with that of the 36 nonpregnant women being 30.75 years and pregnant ones 29.94 years. $52(72.2 \%)$ were married and 56 (77.8\%) were unemployed or earned less than KSH10, 000 (125 US dollars) per month as income. No statistically significant differences were found in the distribution of age, marital status, and income $(P>0.299)$ between the two study groups and in subjects of different trimesters of pregnancy. Statistical difference was however observed in the CD4 absolute count.

The study showed marked and significant lower activated CD8 $\mathrm{T}$ lymphocyte surface markers in pregnant women compared to the nonpregnant group (CD8/HLA-DR \% $(P=$ $0.029)$ and $\mathrm{CD} 8 / \mathrm{CD} 38 \%(P=0.011))$ as depicted in Table 2. Medians found in the $\mathrm{CD}^{+}$cells expressing HLA-DR and CD38 in nonpregnant HIV-infected individuals were 31.6\% and $32.0 \%$, respectively, while in the HIV pregnant women they were $28.4 \%$ and $27.3 \%$, respectively.

Variation of $\mathrm{CD}^{+}$cellular immune activation markers in the pregnant group in different trimesters is as shown in Table 3. The $\mathrm{CD}^{+}{ }^{+} \mathrm{T}$ cell immune activation markers (CD8/HLA-DR/CD38) varied significantly in the different trimesters of pregnancy $(P<0.028)$. The highest percent counts were observed in first trimester with a decrease towards the third trimester. The medians of percent $\mathrm{CD} 8^{+}$ immune activation marker CD8/HLA-DR in the first, second, and third trimesters were $39.2 \%, 28.4 \%$, and $25.3 \%$, respectively. Similarly the CD8/CD38 median percent counts in the subjects in the first, second, and third trimesters were 39.3\%, $28.4 \%, 24.8 \%$, respectively.

The relationship between the activated $\mathrm{CD}^{+} \mathrm{T}$ cells (CD8/HLA-DR/CD38) and $\mathrm{CD}^{+}$cell counts have been 
TABLE 1: Social-economic and demographic characteristics of the study groups.

\begin{tabular}{|c|c|c|c|c|}
\hline Characteristics & Pregnant & Nonpregnant & $P$ value & Total \\
\hline Mean age & $29.94(\mathrm{SD}=4.91)$ & $30.75(\mathrm{SD}=4.62)$ & 0.587 & $30.35(\mathrm{SD}=4.75)$ \\
\hline \multicolumn{5}{|l|}{ Income } \\
\hline Less than 125 US dollars per month & $27(75 \%)$ & $29(80.6 \%)$ & \multirow{2}{*}{0.577} & $56(77.8 \%)$ \\
\hline Equal or more than 125 US dollars per month & $9(25 \%)$ & $7(19.40 \%)$ & & $16(22.2 \%)$ \\
\hline \multicolumn{5}{|l|}{ Marital status } \\
\hline Married & $28(77.8 \%)$ & $24(66.7 \%)$ & \multirow{2}{*}{0.299} & $52(72.2 \%)$ \\
\hline Not married & $8(22.2 \%)$ & $12(33.3 \%)$ & & $20(27.8 \%)$ \\
\hline Absolute CD4 count (median (IQR)) & $442.5(331.5,539.5)$ & $316(178.5,485)$ & 0.004 & \\
\hline WHO staging & Stage I & Stage I & & \\
\hline
\end{tabular}

TABLE 2: Activated CD8T cell percent counts in the study groups (data are median (interquartile range)).

\begin{tabular}{lccc}
\hline Parameters & Pregnant women & Nonpregnant women & $P$ values \\
\hline CD8/HLADR \% & $28.43(23.47,37.49)$ & $31.64(29.25,36.44)$ & $0.029^{*}$ \\
CD8/CD38 \% & $27.29(23.19,36.41)$ & $31.9600(29.0925,36.4775)$ & $0.011^{*}$ \\
\hline
\end{tabular}

${ }^{*}$ Significant $P$ values.

TABLE 3: Activated CD8T cell counts in the pregnant group in different trimesters (data are median (interquartile range)).

\begin{tabular}{lccc}
\hline Parameters & Trimesters & \\
& 1st $(<10 \mathrm{wks})(n=5)$ & 2nd $(10-26$ wks $)(n=14)$ & 3rd $(>26$ wks $)(n=17)$ \\
\hline CD8/HLADR \% & $39.2(32.7,44.5)$ & $28.4(25.7,34.9)$ & $25.3(22.5,38.3)$ \\
CD8/CD38 \% & $39.3(33,44.6)$ & $28.4(25.8,34.9)$ & $24.8(19.6,32.3)$ \\
\hline
\end{tabular}

${ }^{*}$ Significant $P$ values

shown in Tables 4 and 5 . The expression of $\mathrm{CD}^{+} / \mathrm{HLA}-$ $\mathrm{DR}$ (denoted by A) by $\mathrm{CD}^{+} \mathrm{T}$ cells was correlated with CD8/CD38 and CD $4^{+}$cells (all denoted by B). When CD ${ }^{+}$ immune activation markers were correlated in both study groups it was observed that the surface marker $\mathrm{CD}^{+} / \mathrm{HLA}-$ DR positively correlated at $99 \%$ confidence level with $\mathrm{CD}^{+} / \mathrm{CD} 38(P<0.001, r=0.999)$ indicating that when high percent counts of $\mathrm{CD}^{+} / \mathrm{HLA}-\mathrm{DR}$ are observed, high percent $\mathrm{CD}^{+} / \mathrm{CD} 38$ counts were also noted in the study subjects. The percentage of $\mathrm{CD}^{+}{ }^{+}$T cells that were $\mathrm{CD} 38^{+}$and $\mathrm{HLA}-\mathrm{DR}^{+}$had inverse correlations with both the percentage and absolute counts of $\mathrm{CD} 4^{+} \mathrm{T}$ cells in both study groups. However, nonsignificant inverse correlation for the $\mathrm{CD}^{+}$ cellular immune activation markers (HLA-DR and CD38) and $\mathrm{CD} 4^{+}$cell counts was observed in the pregnant study group. In the nonpregnant group $\mathrm{CD} 4^{+}$, absolute cell counts showed a $99 \%$ confidence level of negative correlation with the two surface markers of $\mathrm{CD}^{+}$immune activation (HLADR and CD38). $\mathrm{CD}^{+}$percent cell counts correlated negatively and significantly at $95 \%$ confidence level with the CD $8^{+}$ cellular immune activation markers (HLA-DR and CD38) in the nonpregnant subjects.

\section{Discussion and Conclusions}

The present study investigated how pregnancy alters CD8 $\mathrm{T}$ cell immune activation and how this may correlate with
CD4 counts, as an indicator of immune status. No statistically significant differences were found in the demographics and social economic characteristics between the two groups as shown in Table 1. Pregnancy appears to depress expression of activated CD8 T lymphocytes. It has been shown that the total $\mathrm{CD} 8^{+}$lymphocytes may not be altered by pregnancy [5], but the present study indicates decrease in percentage of activated $\mathrm{CD}^{+} \mathrm{T}$ cells in HIV-infected pregnant women. Progressive suppression was also observed in different trimesters of pregnancy in HIV-infected women as shown in Table 3. This provides evidence that nonpregnant women can expect high turnover and effector function of activated $\mathrm{CD} 8^{+} \mathrm{T}$ cells than pregnancy with HIV infection. The data presented herein support the contention that high levels of CD38 and HLADR expression correlate with $\mathrm{CD}^{+} \mathrm{T}$ cell subset activation in $\mathrm{HIV}^{+}$individuals $[3,6]$. Chronic immune activation and constant turnover of activated $\mathrm{CD}^{+} \mathrm{T}$ cells are therefore a hallmark of HIV infection, and these factors are now thought of as playing a critical role in HIV pathogenesis and disease progression by increased rate of $\mathrm{CD} 4^{+} \mathrm{T}$ cell depletion [7]. CD38 and HLA-DR expression on $\mathrm{CD}^{+} \mathrm{T}$ cell subsets correlated inversely (significantly in nonpregnant subjects) with $\mathrm{CD}^{+} \mathrm{T}$ cell counts as shown in Tables 4 and 5 . This observation suggests that expression of these markers is an important marker for $\mathrm{CD}^{+} \mathrm{T}$ cell activation and $\mathrm{CD} 4^{+}$cell depletion, particularly in HIV infection with no pregnancy. Immune activation-driven death of $\mathrm{CD}^{+}$cells, more than a direct virological pathogenic effect, could be responsible 
TABLE 4: Relationship between CD8/HLA-DR, CD8/38, and the CD4 ${ }^{+}$cell counts (statistical analysis by Pearson correlation (Sig. (2 tailed))).

\begin{tabular}{|c|c|c|c|c|c|}
\hline \multirow{2}{*}{ CD8/HLA-DR \% (A) } & \multirow{2}{*}{ Counts (B) } & \multicolumn{2}{|l|}{ Nonpregnant } & \multicolumn{2}{|l|}{ Pregnant } \\
\hline & & Correlation coefficient $(r)$ & $P$ value & Correlation coefficient $(r)$ & $P$ values \\
\hline & $\mathrm{CD} 8 / 38 \%$ & $r=0.999^{* *}$ & $<0.001$ & $r=0.876^{* *}$ & $<0.001$ \\
\hline & Absolute CD4 & $r=-0.470^{* *}$ & 0.004 & $r=-0.056$ & 0.746 \\
\hline & $\mathrm{CD} 4 \%$ & $r=-0.153$ & 0.374 & $r=-0.022$ & 0.898 \\
\hline
\end{tabular}

A: $\mathrm{CD}^{+} /$HLA-DR cellular immune activation markers; B: CD8/CD38 and CD4 cell counts.

${ }^{* *}$ Correlation is significant at the 0.01 level ( 2 tailed).

TABLE 5: Relationship between CD8/38 and the CD4 ${ }^{+}$cell counts (statistical analysis by Pearson correlation (Sig. (2 tailed))).

\begin{tabular}{cccccc}
\hline CD8/38 \% (A) & Counts (B) & Nonpregnant & & $\begin{array}{c}\text { Pregnant } \\
P \text { values }\end{array}$ \\
& & Correlation coefficient $(r)$ & $P$ value & Correlation coefficient $(r)$ & $r=-0.277$ \\
& Absolute CD4 & $r=-0.478^{* *}$ & 0.003 & $r=-0.162$ & 0.345 \\
\hline
\end{tabular}

A: CD8/38 cellular immune activation markers; B: CD4 cell counts.

${ }^{*}$ C Correlation is significant at the 0.01 level ( 2 tailed).

${ }^{*}$ Correlation is significant at the 0.05 level ( 2 tailed).

for decline in $\mathrm{CD}^{+}{ }^{+} \mathrm{T}$ cells $[7,8]$. Thus, HLA-DR and CD38 expression on $\mathrm{CD}^{+}{ }^{+} \mathrm{T}$ lymphocytes may serve as a tag to identify those $\mathrm{CD}^{+}{ }^{+} \mathrm{T}$ cells that are being eliminated by activation-induced killing during HIV infection. Based on the study results $\mathrm{CD} 8^{+} \mathrm{CD} 38^{+} \mathrm{DR}^{+} \mathrm{T}$ cell level seems to be depressed in pregnant HIV-infected patients and therefore may be an important prognostic parameter of immune status during pregnancy. The present study design could not show the cause-effect relationship but gave a mere comparison of study groups and relationships of variables; this could be rigorously studied using follow-up study design with more control arms including viral load counts to validate the observed results.

\section{Conflict of Interests}

The authors declare that there is no conflict of interests regarding the publication of this paper.

\section{Acknowledgment}

The authors most gratefully acknowledge Moi University, MTRH, and AMPATH staff for their support during the research process. They also appreciate the study participants for their participation.

\section{References}

[1] D. L. Sodora and G. Silvestri, "Immune activation and AIDS pathogenesis," AIDS, vol. 22, no. 4, pp. 439-446, 2008.

[2] Y. Mikyas, N. Aziz, N. Harawa et al., "Immunologic activation during pregnancy: serial measurement of lymphocyte phenotype and serum activation molecules in HIV-infected and uninfected women," Journal of Reproductive Immunology, vol. 33, no. 2, pp. 157-170, 1997.

[3] H. Imamichi, R. A. Lempicki, J. W. Adelsberger et al., "The CD8+ HLA-DR+ T cells expanded in HIV-1 infection are qualitatively identical to those from healthy controls," European Journal of Immunology, vol. 42, pp. 2608-2620, 2012.

[4] Z. Zhang, S. Hu, J. Liu et al., "CD4+CD38+HLA-DR+Cells: a predictor of viral set point in Chinese men with primary HIV infection who have sex with men," Japanese Journal of Infectious Diseases, vol. 64, no. 5, pp. 423-425, 2011.

[5] S. Musyoki, S. Mining, and P. Nyongesa, "Comparison of white blood cells and lymphocytes between pregnant and non-pregnant women infected with human immunodeficiency virus," Asian Journal of Pharmaceuticals and Health Sciences, vol. 2, no. 4, pp. 562-565, 2012.

[6] P. Burgisser, C. Hammann, D. Kaufmann, and P. C. Frei, "Expression of CD28 and CD38 by CD8+ T cells in HIV infection correlates with viral load and CD4+ $\mathrm{T}$ cell number at baseline and during treatment," in Proceedings of the 12th International AIDS Conference, p. 529, Geneva, Switzerland, 1998.

[7] P. W. Hunt, J. N. Martin, E. Sinclair et al., "T cell activation is associated with lower CD4+ T cell gains in human immunodeficiency vires-infected patients with sustained viral suppression during antiretroviral therapy," Journal of Infectious Diseases, vol. 187, no. 10, pp. 1534-1543, 2003.

[8] D. N. Burns, P. Nourjah, D. J. Wright et al., "Changes in immune activation markers during pregnancy and postpartum," Journal of Reproductive Immunology, vol. 42, no. 2, pp. 147-165, 1999. 


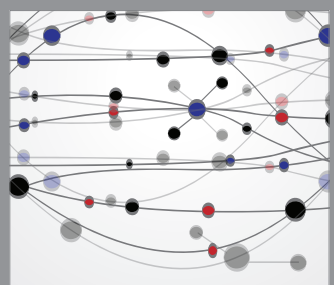

The Scientific World Journal


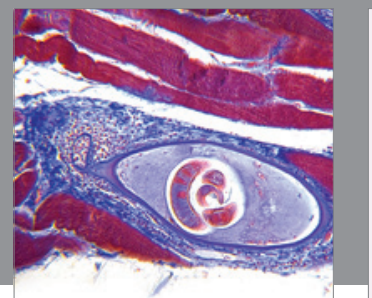

Gastroenterology

Research and Practice
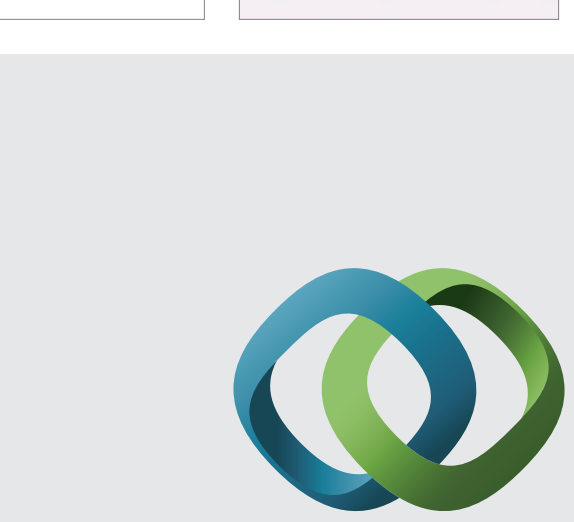

\section{Hindawi}

Submit your manuscripts at

http://www.hindawi.com

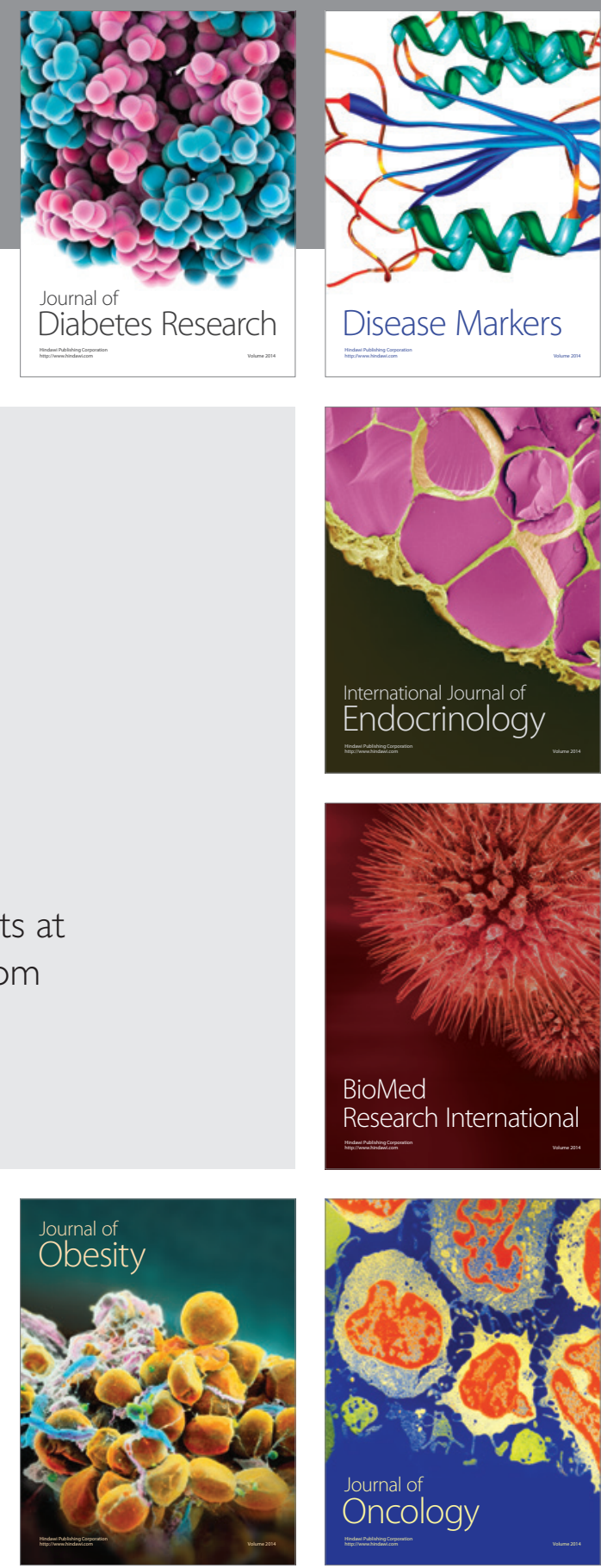

Disease Markers
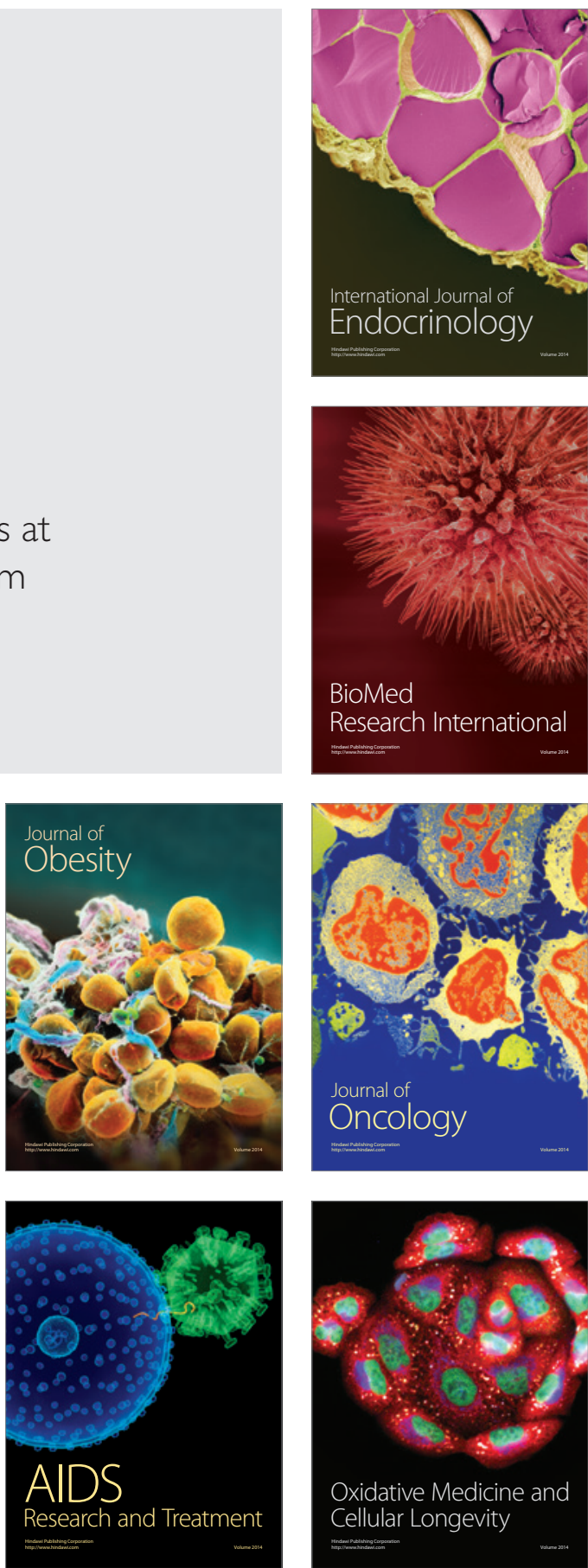